\title{
A 56-year-old man with RT-PCR negative nasopharyngeal swabs with Coronavirus Disease 2019 (COVID-19) Pneumonia
}

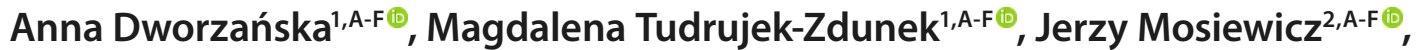 \\ Lech Panasiuk ${ }^{3, A-F}{ }^{2}, K^{\prime}$ rzysztof Tomasiewicz ${ }^{1, A-F} \oplus$ \\ ${ }^{1}$ Chair and Department of Infectious Diseases, Medical University, Lublin, Poland \\ ${ }^{2}$ Chair and Department of Internal Diseases, Medical University, Lublin, Poland \\ ${ }^{3}$ Institute of Rural Health, Lublin, Poland \\ A - Research concept and design, B - Collection and/or assembly of data, C - Data analysis and interpretation, \\ $D$ - Writing the article, E - Critical revision of the article, F - Final approval of article
}

Dworzańska A, Tudrujek-Zdunek M, Mosiewicz J, Panasiuk L, Tomasiewicz K. A 56-year-old man with RT-PCR negative nasopharyngeal swabs with Coronavirus Disease 2019 (COVID-19) Pneumonia. Ann Agric Environ Med. 2020; 27(2): 317-318. doi: 10.26444/aaem/123543

\section{Abstract}

Introduction. Diagnostic procedure in Coronavirus Disease 2019 (COVID-19) is based mainly on performing real-time-reverse transcription-polymerase chain-reaction (RT-PCR), which has been accepted as the gold standard method. In some cases, such as mutations of the SARS-CoV-2 genome, variable viral load kinetics or laboratory errors, it can be false-negative.

Case report. The case is presented of a 56-year-old man with respiratory tract symptoms, with twice negative results of realtime-reverse transcription-polymerase chain-reaction of nasopharyngeal swabs and positive chest computed tomography, with typical findings for COVID-19 pneumonia.

Conclusions. Patients with negative RT-PCR results, but with positive computed tomography findings characteristic for COVID-19, should be treated as well as those infected.

\section{Key words}

RT-PCR, pneumonia, Covid-19, Coronavirus Disease 2019, chest computed tomography, real-time-reverse transcription-polymerase chain-reaction

\section{INTRODUCTION}

The current outbreak of COVID-19 caused by the severe acute respiratory syndrome coronavirus 2 (SARS-CoV-2) was first reported in China and has spread rapidly in multiple countries $[1,2]$. The clinical spectrum of COVID-19 can range from asymptomatic, or with only mild symptoms of illness to severe pneumonia and death [3]. Considering that in some cases, clinicians obtained negative results of reverse transcription polymerase chain reaction (RT-PCR) swabs in patients whose clinical features indicates COVID-19, there is need to perform computed tomography (CT) as a more sensitive diagnostic tool to confirm infection.

\section{CASE REPORT}

A 56-year-old man who returned from Holland was admitted to the Department of Infectious Diseases of the Medical University in Lublin with subfebrile state and muscle pain lasting for 7 days, and dry cough for 2 days. He had a history of last contact with one COVID-19 case 4 days before first symptoms. He had no significant medical history. Physical examination revealed a temperature of $38.3^{\circ} \mathrm{C}$, pulse rate 118 beats/minute, respiratory rate 17 breaths/minute, blood pressure $140 / 97 \mathrm{mmHg}$, and oxygen saturation 93\%. Auscultation indicated left-side-crackles. There was no cyanosis and no use of accessory respiratory muscles. His condition was stable, he did not present with dyspnea or other alarming symptoms.

Address for correspondence: Anna Dworzańska Chair and Department of Infectious Diseases, Medical University, Lublin, Poland

E-mail:annadw8@gmail.com

Received: 05.05.2020; accepted: 04.06.2020; first published: 19.06.2020
In the initial blood tests, mild thrombocytopenia (112 000/ul) was noticed, a slight increase of C-reactive protein $(16.4 \mathrm{mg} / \mathrm{l})$, but no other abnormalities (Tab. 1).

The first chest radiography showed an intensified bronchial pattern of the lower lobe of the right lung. He had a negative result of RT-PCR SARS-CoV-2 nasopharyngeal swab obtained on the day of admission. It was decided to start empirical treatment with ceftriaxone and azithromycin. After 2 days, information was received about the positive result of SARSCoV-2 RT-PCR of patient's wife, who was asymptomatic. The patient's condition did not improve. It was decided to perform a second chest radiography where the progression of lesions was noted, described as a parenchymal density in the right lung and small focal parenchymal density in the left lung. Also of importance were the negative results of cytomegalovirus (CMV), respiratory syncytial virus (RSV) and influenza $A$ and $B$ virus infections. Because of the high likelihood of COVID-19, treatment was started with chloroquine (500 mg/twice per day) and lopinavir/ritonavir (400 mg/100 mg/twice per day).. Crackles were heard on both lungs. A CT scan of the chest was performed which showed patchy disseminated, multifocal ground-glass opacity (GGO) in both lungs, and interlobular septal thickening (crazy paving appearance). In the lower part of the right lobe there was an atoll sign (reversed halo sign). These lesions were typical for COVID-19 (Fig. 1). For distinctive CT changes with negative RT-PCR results, the serological test results would prove had no access to any reliable serological tests that could be used to test the patient.

The treatment was effective and well tolerated. Fever and respiratory tract symptoms resolved, regression of lesions in chest X-ray were also obtained. The patient was discharged in good condition after 14 days of hospitalization. 
Table 1. Laboratory findings during hospitalization

\begin{tabular}{lccccccccccc}
\hline & $\begin{array}{c}\text { WBC } \\
{[\mathrm{K} / \mathrm{ul}]}\end{array}$ & $\begin{array}{c}\text { NEU } \\
{[\mathrm{K} / \mathrm{ul}]}\end{array}$ & $\begin{array}{c}\text { LYMP } \\
{[\mathrm{K} / \mathrm{ul}]}\end{array}$ & $\begin{array}{c}\text { PLT } \\
{[\mathrm{K} / \mathrm{ul}]}\end{array}$ & $\begin{array}{c}\text { Creatinine } \\
{[\mathrm{mg} / \mathrm{dl}]}\end{array}$ & $\begin{array}{c}\text { ALT } \\
{[\mathrm{U} / \mathrm{ll}]}\end{array}$ & $\begin{array}{c}\text { CRP } \\
{[\mathrm{ml} / \mathrm{l}]}\end{array}$ & $\begin{array}{c}\text { LDH } \\
{[\mathrm{IU} / \mathrm{l}]}\end{array}$ & $\begin{array}{c}\text { TG } \\
{[\mathrm{mg} / \mathrm{dl}]}\end{array}$ & $\begin{array}{c}\text { IL-6 } \\
{[\mathrm{pg} / \mathrm{ml}]}\end{array}$ & $\begin{array}{c}\text { D-dimer } \\
{[\mathrm{ng} / \mathrm{ml}]}\end{array}$ \\
\hline Day 0 & 5.79 & 4.08 & 1.42 & 121 & 1.16 & 33.9 & 16.4 & 406 & 299 & 18.83 & 359 \\
\hline Day 14 & 5.31 & 2.28 & 2.33 & 262 & 1.19 & 44.7 & 2.1 & 385 & 342 & 4.35 & $<215$ \\
\hline
\end{tabular}

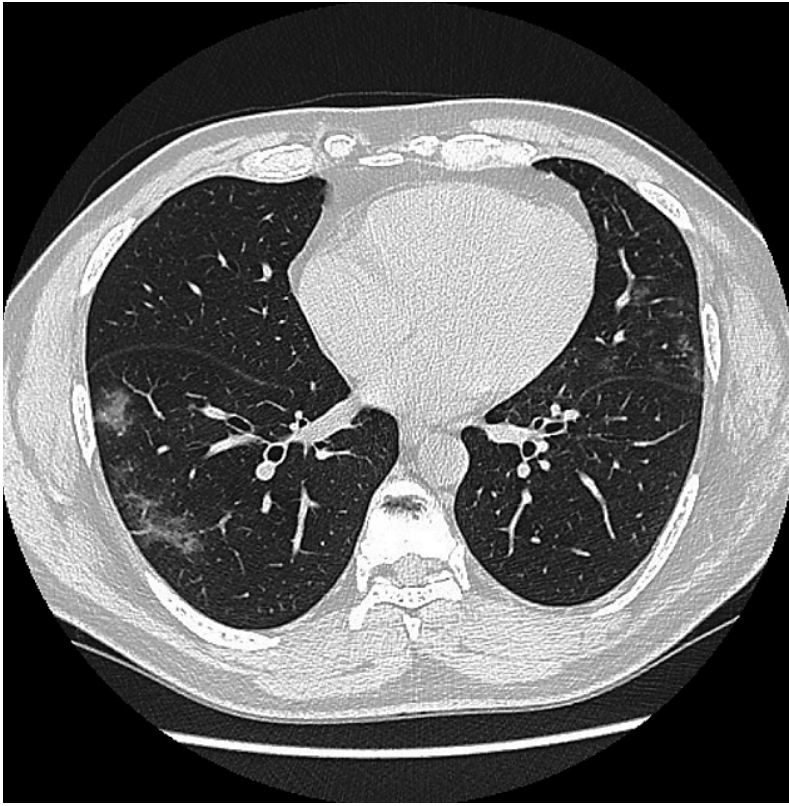

Figure 1. Features of COVID-19 pneumonia in chest CT.

\section{DISCUSSION}

Diagnosis of COVID-19 should be confirmed by performing RT-PCR or gene sequencing for respiratory or blood specimens. RT-PCR is a test for qualitative detection of nucleic acid from SARS-CoV-2 in upper and lower respiratory specimens (nasopharyngeal, oropharyngeal swabs, sputum, lower respiratory tract aspirates, bronchoalveolar lavage and nasopharyngeal wash/aspirate or nasal aspirate) [4]. Although RT-PCR is regarded as a reference standard, recent studies have revealed its low sensitivity: $60-71 \%$ for detecting COVID-19 [5]. There are some factors that can be associated with the inconsistency of RT-PCR: variation of viral RNA sequences (genetic diversity and its rapid evolution), mutations in particular regions in the SARS-CoV-2 genome, viral load kinetics, and sampling procedure (inappropriate collection, transportation or laboratory facilities) $[6,7]$.

Most reports have noted that a crucial role in the COVID-19 diagnostic process is played by a chest CT with its high sensitivity [8]. Some of authors confirmed the importance of chest computed tomography (CCT) examination in COVID-19 patients with false negative RT-PCR results, and reported CT sensitivity as $98 \%[8,9]$. Tao Ai et al. examined 1,014 patients in Wuhan and performed chest CT and RTPCR tests. 59\% of patients had positive RT-PCR results and $88 \%$ had positive chest CT scans. Additionally, they noticed that $75 \%$ of patients with negative results of RT-PCR had positive chest CT, which makes this imaging diagnostic method a very valuable tool for COVID-19 detection [10]. The important role of chest CT in diagnosing COVID-19 was also confirmed in another study where authors indicated that a combination of RT-PCR and CT has a higher sensitivity than RT-PCR alone, or CT alone or 2 RT-PCRs [11]. According to many data, there are also some characteristic alterations of particular laboratory parameters that are observed more commonly in patients with COVID-19. It is reported that severe cases more often present with a significantly higher level of alanine aminotransferase (ALT), aspartate aminotransferase (AST), lactate dehydrogenase (LDH), C-reactive protein (CRP), ferritin, D dimers, procalcitonin, higher levels of IL-2R, IL-6, IL-10, TNF-alpha, as well as lymphopenia, hypoalbuminaemia in comparison with cases of moderate course [3]. The vast majority of studies indicate that the main features in CT scans in COVID-19 pneumonia are: ground-glass opacity with peripheral and subpleural distribution, a crazy-paving pattern, and the reversed halo sign. Lesions are usually located in multiple lobes, often in the lower parts of the lungs. Similar symptoms can be also present in pneumonia caused by other causative agents. In such patients, a differential diagnosis should be considered, with such alternatives as influenza pneumonia, RSV pneumonia, Mycoplasma pneumonia, or with chemical toxicity or some lesions after radiotherapy [12]. In the presented case, it was shown that patient had radiological features typical for COVID-19, characteristic alterations in laboratory blood tests with negative results of RT-PCR, and was treated as a positive case.

\section{REFERENCES}

1. Gorbalenya AE, Baker SC, Baric RS, et al. Severe acute respiratory syndrome related coronavirus: The species and its viruses a statement of the Coronavirus Study Group. Microbiology. 2020 Feb 19. doi: $/ 10.1101 / 2020.02 .07 .937862$

2. Centers for Disease Control and Prevention (CDC). Coronavirus Disease 2019 (COVID-19). Atlanta; 2020. Available from https://www. cdc.gov/coronavirus/2019-ncov/index.html.

3. Guang Chen, Di Wu, Wei Guo, et al. Clinical and immunologic features in severe and moderate forms of Coronavirus Disease 2019. J Clin Invest. 2020 Apr 12. doi: 10.1172/JCI137244

4. Wang X, Tan L, Wang X, et al. Comparison of nasopharyngeal and oropharyngeal swabs for SARS-CoV-2 detection in 353 patients received tests with both specimens simultaneously. Int J Infect Dis. 2020 Apr 94: 107-109

5. Fang Y, Zhang H, Xie J, et al. Sensitivity of Chest CT for COVID-19: Comparison to RT-PCR. Radiology. 2020 Feb 19. doi: 10.1148/ radiol.2020200432

6. Tahamtan A, Abdollah A. Real-time RT-PCR in COVID-19 detection: issues affecting the results. Expert Rev Mol Diagn. 2020 Apr 22: 1-2. doi: 10.1080/14737159.2020.1757437

7. Phan T. Genetic diveristy andevolution of SARS-CoV-2. Infect Genet Evol. 2020 Feb 21(81): 104260

8. Xie X, Zhong Z, Zhao W, et al. Chest CT for Typical 2019-nCoV Pneumonia: Relationship to Negative RT-PCR Testing. Radiology. 2020 Feb 12. doi: 10.1148/radiol.2020200343

9. Huang P, Liu T, Huang L, et al. Use of chest CT in combination with negative RT-PCR assay for the 2019 novel coronavirus but high clinical suspicion. Radiology. 2020 Feb 12. doi: org/10.1148/radiol.2020200330

10. Tao Ai, Yang Z, Hou H, et al. Coronavirus Disease 2019 (COVID-19) in China: A Report of 1014 Cases. Radiology. 2020 Feb 26. doi: 10.1148/ radiol.2020200642

11. Jiang GM, Ren X, Liu Y, et al. Application and optimization of RT-PCR in diagnosis of SARS-CoV-2-infection. Lancet Infect Dis. 2020 Feb. doi: 10.1101/2020.02.25.20027755

12. Bai HX, Hsieh B, Xiong Z, et al. Performance of Radiologists in Differentiating COVID-19 From Viral Pneumonia on Chest CT. Radiology. 2020 Mar 10. 200823. doi: 10.1148/radiol.2020200823 